\title{
IMPACTOS DAS POLÍTICAS PÚBLICAS DO TRABALHADOR DA EDUCAÇÃO NA REDE ESTADUAL DE ENSINO DE PATOS DE MINAS/MG EM 2011
}

\author{
PUBLIC POLICY IMPACTS OF WORKER EDUCATION NETWORK OF STATE \\ SCHOOL OF PATOS DE MINAS / MG 2011
}

\author{
Rosana Mendes Maciel ${ }^{*}$ \\ Fabiane Santana Previtali**
}

\begin{abstract}
RESUMO
O presente trabalho consiste na concretização de uma pesquisa de Mestrado, pertencente ao Programa de Pós-Graduação Stricto Sensu em Educação da Universidade Federal de Uberlândia, na linha de pesquisa intitulada "Políticas e Gestão em Educação". Trata-se do trabalho realizado através de leituras, debates e reflexões desenvolvidas no Grupo de Pesquisa Trabalho, Educação e Sociedade - GPTES e conta com o apoio da Coordenação de Aperfeiçoamento de Pessoal de Nível Superior - CAPES. O estudo discute a reestruturação produtiva na esfera educacional e seus impactos no trabalho docente da rede pública estadual de Minas Gerais, a partir de 1990 quando se intensificam as reformas educacionais no Brasil, particularmente em Minas Gerais. $O$ estudo inclui revisão de literatura, análise de documentos e pesquisa empírica na forma de estudo de caso. Tais reflexões estão fundamentadas em uma pesquisa empírica, realizada no município de Patos de Minas/MG. A pesquisa foi desenvolvida através da discussão teórica acerca da articulação dialética entre educação e trabalho, demonstrando também as modificações ocorridas com o processo de reestruturação produtiva.
\end{abstract}

PALAVRAS-CHAVE: Educação Básica - Trabalho Docente - Reestruturação Produtiva.

\begin{abstract}
This work is the realization of a Master's Degree research, belonging to the Postgraduate studies in Education at the Federal University of Uberlândia, in the line of survey entitled "Policies and Management in Education." This is the work done through readings, discussions and reflections developed in the Research, Labor, Education and Society Group - GPTES and have the support of the Coordination of Improvement of Higher Education Personnel - CAPES. The study discusses the restructuring of production in the educational sphere and its impact on teaching the public state of Minas Gerais, since 1990 when they intensify the education reforms in Brazil, particularly in Minas Gerais. The study includes literature reviews, analysis of documents and empirical research in the form of case study. Such reflections are grounded in empirical, research conducted in the city of Patos de Minas / MG. The survey was developed through a theoretical discussion about


the dialectical link between education and work, also showing the changes that occurred with the restructuring process.

KEYWORDS: Basic Education - Teaching - Productive Restructuring.

\section{INTRODUÇÃO}

O presente estudo insere-se no âmbito das investigações sobre políticas e gestão em Educação e tem como temática a reestruturação produtiva na Educação, particularmente as reformas educacionais na educação básica a partir da década de 1990 e seus impactos sobre o trabalho docente na rede estadual de Patos de Minas - MG.

Sendo assim, o objetivo geral desse trabalho é analisar a reestruturação produtiva, particularmente as reformas educacionais e seus impactos no trabalho docente da rede pública estadual de Minas Gerais, a partir de 1990 quando se intensificam as reformas educacionais no Brasil e em Minas Gerais. Para tanto, buscase contextualizar a reestruturação da educação e do trabalho docente no cenário de mundialização do capital, especialmente no âmbito nacional, face às reformas educacionais dos anos 1990, o estudo inclui revisão de literatura, análise de documentos de órgãos responsáveis por deliberar sobre políticas públicas educacionais no Brasil.

Realizou-se ainda uma pesquisa empírica sobre a temática junto ao Sindicato Único dos Trabalhadores em Educação - SindUTE da cidade de Patos de Minas/MG. Foram realizadas entrevistas com três membros da diretoria do sindicato no $2^{\circ}$ semestre de 2011.

O estudo bibliográfico envolveu a discussão sobre a temática do capitalismo, inserida no conceito histórico da reestruturação produtiva do mundo do trabalho frente à reconfiguração do cenário político mundial. O estudo bibliográfico analisou os periódicos de maior relevância na área em articulação com a atual literatura referente à temática abordada, com fundamentos tanto no pensamento clássico ou interpretações do desenvolvimento brasileiro.

Por fim, foram realizadas entrevistas com três membros da diretoria do Sindicato Único dos Trabalhadores em Educação de Minas Gerais - SindUTE/MG na 
cidade de Patos de Minas para análise comparativa entre a literatura existente sobre a temática e o discurso do SindUTE/MG.

As entrevistas foram norteadas por questões fechadas e semi-abertas, de forma a compreender-se como o sindicato que representa os professores da rede estadual, analisa a reestruturação produtiva na educação e seus impactos no trabalho docente, bem como a sua função política em relação a esse processo.

De posse dos referenciais teóricos e documentos legais, foi realizado um confronto e análise de todos os dados encontrados no desenvolvimento da pesquisa.

Para a análise das entrevistas semi-estruturadas, foi verificada a freqüência das respostas apresentadas, bem como uma análise crítica do conteúdo dessas respostas. As perguntas das entrevistas destinadas aos membros do SindiUTE foram construídas objetivando fornecer um diagnóstico da situação vivenciada pelos professores frente às políticas públicas de caráter neoliberal em âmbito nacional e estadual.

\section{AS REFORMAS EDUCACIONAIS NO CONTEXTO DA REESTRUTURAÇÃO PRODUTIVA NOS ANOS 1990}

Há na literatura uma significativa problematização sobre políticas educacionais e reformas de ensino que discutem os impactos da globalização econômica e da hegemonia política do neoliberalismo sobre a educação brasileira.

Esses estudos tendem a vincular as transformações em curso no campo educacional e no trabalho docente à emergência no pós-guerra de uma nova ordem econômica internacional que altera profundamente os processos econômicos e as relações de trabalho, mas também o campo da cultura e os modos de existência e subjetividade dos indivíduos e grupos sociais.

Segundo Kuenzer (1997):

Embora não sejam a principal causa, os avanços da ciência e da tecnologia, resultantes do investimento do grande capital e dos Estados Nacionais, passam a ser estruturalmente constituintes do novo modo de acumulação, contribuindo desta forma para o desemprego não apenas porque os investimentos geram poucos postos, mas também porque os geram no setor mais dinâmico, que não por acaso vem sistematicamente substituindo a força de trabalho pela tecnologia, 
como estratégia de competitividade e imperativo de sobrevivência das grandes empresas no âmbito da internacionalização.(KUENZER, 1997, s/p)

No caso específico das políticas educacionais, a ênfase da reforma foi originar autonomia administrativa, financeira e pedagógica para as escolas, com o objetivo de possibilitar sua gestão por meio da participação dos seus professores e funcionários, pais e alunos. Esses objetivos vão de encontro aos interesses clientelistas, na medida em que a educação surge, historicamente, entre as políticas utilizadas com finalidades eleitorais pelo Estado.

Nogueira discorrendo sobre a reforma afirma que

As políticas de formação de professores, a partir de 1995, têm como objetivo central ajustar o perfil do professor e a formação docente às demandas do "novo" mercado de trabalho, em um período marcado por novos padrões de produção, no interior da reestruturação da forma de acumulação capitalista. (NOGUEIRA, 2003, p. 22).

No processo das reformas, o governo atribui um valor específico à educação pelo seu ressignificado de valores específicos do capitalismo para ajustamento da educação às demandas do mercado, diante de estratégias que buscam adequar a escola e seus profissionais aos interesses hegemônicos para manter as condições de acumulação capitalista.

No aspecto destas políticas, o processo de flexibilização das instituições formadoras de docentes, assim como do perfil destes profissionais, apresentou ações estratégicas para adequá-los às novas necessidades do mercado de trabalho no atual estágio de racionalidade técnico-científica dos processos profissionais. .Ressalta-se, que essencialmente todo o processo de reforma do Estado, que busca a realização de uma política de ajuste estrutural e da estabilidade econômica, insere-se a reforma educacional brasileira (LEHER, 1998).

As reformas educacionais ocorridas a nível mundial nos anos de 1990 e com co modificações contínuas nesse novo milênio procuram traduzir as demandas postas pela lógica capitalista. Assim, as reformas praticadas nos últimos anos surgem dos 
princípios de alterações econômicas designadas pela globalização, o que exige maior eficiência e produtividade dos trabalhadores com a finalidade de adaptação às exigências do mercado. É importante ressaltar que as reformas se apresentam politicamente bem definidas e incluem a estrutura administrativa e pedagógica da escola, a formação de professores, os conteúdos a serem ensinados, os fundamentos teóricos a serem seguidos e o modelo de gestão a ser aplicado. Malanchen e Vieira (2006) afirmam que

É nesse contexto que os órgãos governamentais brasileiros evidenciam a necessidade de adequação do trabalho docente às novas exigências profissionais advindas das inovações tecnológicas e da conseqüente mudança do mundo do trabalho apregoado pelos princípios de flexibilidade e eficiência. Desse modo, o Estado regulador e avaliador têm intervido na questão, procurando instituir mecanismos que induzam os docentes a adequarem as atividades inerentes à profissão de acordo com os resultados estabelecidos pelos interesses mercantilistas. ( MALANCHEN \& VIEIRA, 2006, p.6)

Por meio de recomendações vindas de documentos dos organismos internacionais, os órgãos responsáveis, promulgaram a reformulação da política educacional brasileira e na América Latina que demonstra os seguintes pressupostos: a ampliação de acesso à educação básica, a diversificação das instituições de ensino superior e dos cursos e a diversificação das fontes de financiamento deste nível de ensino. Esses pressupostos são apresentados como elementos significativos para a criação de uma pseudo-democratização e do crescimento da escolarização, escondendo dois fenômenos que ocorrem nos países periféricos: a aceleração da formação inicial e o processo de certificação em larga escala.

Inseridas nesse contexto, as reformas educacionais executadas no Brasil foram autenticadas por um discurso que atribuiu à crise da educação a ineficiência de aspectos específicos como gestão, má formação dos professores, currículos inadequados, falta de insumos, entre outros.

O governo brasileiro criou o consenso da importância da reforma educacional embasado nas críticas realizadas pelos organismos internacionais que demonstravam a ineficiência do Estado como principal responsável por gerir a Educação e o responsabilizaram pela crise do sistema educacional. $O$ entendimento de que intervenção 
do Estado prejudicava a concretização de uma educação de qualidade foi um dos aspectos mais defendidos pelas políticas de reforma.

As reformas educacionais dos anos de 1990 apresentaram como eixo principal a educação para a eqüidade social. Essa alteração de paradigma implica transformações fundamentais na organização e na gestão da educação pública. Passa a ser uma ordem dos sistemas escolares a formação de indivíduos para a empregabilidade, já que a educação geral é apresentada como requisito indispensável ao emprego regulamentado e formal, ao mesmo tempo em que deveria desempenhar papel indispensável na condução de políticas sociais compensatórias com vistas à redução da pobreza.

Nos países economicamente dependentes como o Brasil, as racionalidades neoliberais na esfera educacional são objeto de intensas contestações, tendo os governos que recuar diante das dificuldades e dos embates que essas medidas na maioria das vezes suscitam, seja pela comunidade científica e dos sindicatos de professores e/ou pelas dificuldades que essas políticas enfrentam no momento de serem recontextualizadas no interior das instituições educacionais.

Dale (2004) permite compreender as relações fundamentais entre a necessidade de manter e fortalecer o sistema capitalista, as mudanças na economia mundial, as alterações nas políticas educacionais e a atuação decisiva dos organismos internacionais, que definem modelos curriculares atrelando financiamentos à adesão a suas orientações e abordagens em educação.

As reformas educacionais brasileiras apresentam como característica comum a "tentativa de melhorar as economias nacionais pelo fortalecimento dos laços entre escolarização, trabalho, produtividade, serviços e mercados" sendo vista pelos governantes como uma possibilidade de ingresso no marcado capitalista mundial. (AZEVEDO, 2004, p.7-8).

De acordo com Oliveira (2004)

O argumento central dessas reformas poderia ser sintetizado na expressão largamente utilizada nos estudos produzidos pelos organismos internacionais pertencentes à ONU para orientação dos governos latino-americanos com relação à educação: transformação produtiva com eqüidade. (OLIVEIRA, 2004, p.1132) 
$\mathrm{Na}$ emblemática relação entre universalização e equidade, foi realizada a Conferência Mundial sobre Educação para Todos, em Jomtien, na Tailândia, em março de 1990, onde os 155 países participantes, dentre eles, o Brasil, firmaram o compromisso de universalizar o ensino fundamental em um prazo de dez anos.

A Conferência Mundial sobre Educação para Todos afirmou a tentativa de uma nova orientação da educação para a eqüidade social perante as reformas educacionais dos países mais pobres e populosos do mundo. Para cumprir o compromisso de expandir a educação básica, estabelecido na Tailândia, os países economicamente dependentes tiveram que repensar estratégias de aumento do nível de atendimento às populações sem, contudo, elevar os investimentos na mesma proporção. A diminuição das desigualdades sociais deveria ser alcançada a partir da expansão da educação, que permitiria às pessoas em situação vulnerável encontrar novos caminhos para a sua sobrevivência (CARNOY, 1992).

Para acompanhar as tendências neoliberais mundiais, o governo de Fernando Henrique Cardoso, criou o Planejamento Político-Estratégico do Ministério de Educação e Cultura - MEC, com a finalidade de orientar as reformas educacionais. (SILVA JÚNIOR, 2002).

Entre as metas desse documento estão a descentralização da administração das verbas federais, elaborações do currículo básico nacional, educação a distância, avaliação nacional das escolas, incentivo à formação de professores, entre outros. Nesse contexto iniciou-se uma ampla reforma educacional, com a aprovação da Lei de Diretrizes e Bases da Educação Nacional - LDB 9.394/96, em 20 de dezembro de 1996. Sob a óptica da LDB 9.394/96 surgiram as denominadas reformas educacionais dos anos 1990, sob a perspectiva de projetar as políticas educacionais nos moldes neoliberais. A educação passa a ser inserida em um contexto de empregabilidade, com a noção de equidade, e não mais de igualdade. A educação passa a ser orientada "para todos" (OLIVEIRA, 2004),

Com o objetivo de regulamentar a formação de professores, foram aprovadas em 2002 as Diretrizes Curriculares Nacionais para a Formação de Professores da 
Educação Básica. Nessas diretrizes, Silva (2007) aponta que o eixo da formação docente passa a ser o que e o como ensinar, privilegiando as dimensões técnica e praticista do trabalho docente e proporcionando uma reprodução maciça de profissionais exclusivos para o mercado de trabalho. (SILVA, 2007)

Neste processo, muitos professores perdem a identidade como classe trabalhadora, os quais aderem ao projeto político burguês, transmitindo os conceitos de empreendedorismo, competitividade, inteligência emocional, polivalência, com uma formação que conduz à articulação entre competência e compromisso, e promove assim a precarização na formação dos professores. A fragmentação é utilizada também para que o professor não se sinta pertencente a uma categoria. Através da divisão das especialidades - administrador, supervisor, orientador, coordenador - o trabalhador docente não se identifica mais como professor, e trabalhando em diversas escolas, não se identifica nem com a escola em que trabalha, nem com os problemas da mesma. De acordo com Adami et al (2006)

Todavia esta divisão do trabalho escolar tem origem na separação entre propriedade dos meios de produção e força de trabalho, e não na divisão técnica do trabalho.Porém, percebe-se a compreensão e o interesse que a classe dominante tem em relação à escola, quando considera que compete a ela dar uma formação que possibilite o manuseio das máquinas que serão utilizadas nos mercados de trabalho e de consumo. (ADAMI ET AL, 2006, p.247)

A função da escola passa a ser a de instruir as pessoas com algum de conhecimento informações úteis para que seja possível realizarem suas tarefas, mas não com o conhecimento do processo produtivo em sua totalidade, pois se o trabalhador tiver acesso a uma educação mais complexa, poderá perceber sua condição de explorado.

Nagel (2001, p. 5), embasado no materialismo histórico contribui nessa compreensão ao escrever:

O planejamento internacional para o desenvolvimento da sociedade capitalista implica não só em generalizar o conhecimento para todos os países do globo como em selecionar o conhecimento que pode ou deve ser adquirido pelos indivíduos de países "em desenvolvimento". Limitando o saber dos cidadãos de segunda classe", assegurando uma valorização desmedida à informação, sem interesse em estimular o conhecimento, quer como processo mental, quer como saber sistematizado, uma nova forma de exclusão é garantida sob a capa de uma ideologia igualitária. E,

\author{
Revista LABOR
}

n6, v.1, 2011

ISSN: 19835000 
nessa modernidade, a maioria dos cidadãos, sem luta, sem oposição e sem contestação, pode ser incluída, porque já vem perdendo, gradativa, mas aceleradamente, a capacidade de formular problemas.(NAGEL, 2001, p.5)

Esse novo modelo de formação de professores colaborou para a precarização da formação docente, desvalorizando as dimensões políticas e éticas da formação e apresenta um retrocesso à luta dos educadores pela melhoria da qualidade educacional do país. (BRITO, 2008). Outro aspecto importante a ser observado relaciona-se ao processo de avaliação escolar, aprovado na LDB 9394/96, o que demonstra a forte preocupação com o controle de resultados.

A LDB 9.394/96 aprovou criação de um fundo para o financiamento da educação, o Fundo de Manutenção e Desenvolvimento do Ensino Fundamental e de Valorização dos Profissionais do Magistério - FUNDEF, que proporcionou uma forma de descentralização, distribuindo as competências frente à educação para os estados e municípios. (AUGUSTO, 2004).

A LDB 9394/96, além de instituir a municipalização do ensino, ampliou as atribuições docentes, nas quais os professores passaram a se preocupar, além das questões relativas ao ensino-aprendizagem, com as atividades de gestão, planejamento, assistência e acompanhamento e integração escola-família-comunidade. A nova LDB modificou a organização escolar, com ampliação de 180 para 200 dias letivos, avaliação do aluno pelo rendimento escolar, participação da comunidade. Essas mudanças repercutiram diretamente no trabalho do professor, com o aumento de tarefas durante a jornada de trabalho e aumento das responsabilidades de decisão na comunidade escolar.

De acordo com Silva (2007)

Sob pontos de vista divergentes e variados enfoques teóricos e metodológico, a literatura educacional aponta em quase uníssono que o trabalho docente está passando por mudanças. Estudos nos indicam que estas se referem, essencialmente, a preocupações em torno da formação de professores e da qualidade da educação e a ações de precarização e flexibilização do trabalho, envolvidos na crise do Estado sob hegemonia neoliberal. (SILVA, 2007, p.1) 
Miranda (2006) faz uma reflexão sobre a redução do grau de autonomia do professor, através da ampliação da jornada de trabalho, do rebaixamento do nível de qualificação e da flexibilização do trabalho docente. Portanto, a reestruturação produtiva modificou a forma de trabalho docente, através de mecanismos de profissionalização - precarização do trabalho docente, como estratégia imposta pelo neoliberalismo.

Inserida no contexto de acumulação flexível sob a ótica neoliberal do capitalismo, as reformas educacionais aparecem como uma "tentativa de melhorar as economias nacionais pelo fortalecimento dos laços entre escolarização, trabalho, produtividade, serviços e mercados". (AZEVEDO, 2004, p.9).

A ótica neoliberal no contexto educacional estimula uma moral de autorresponsabilização e culpa por parte dos professores, que, aliada à deterioração dos salários e das condições de trabalho, vem contribuindo para a intensificação e autointensificação do trabalho docente e para a geração de frustrações e desencantos. O modelo de gestão escolar implementado passa a ser baseado na junção de formas de planejamento e controle central na organização de políticas, associado à descentralização administrativa na implementação dessas políticas. Essas estratégias possibilitam a organização local como o complemento orçamentário com recursos de parcerias e da comunidade envolvida. A eqüidade far-se-ia presente principalmente nas políticas de financiamento, a partir da definição de custos mínimos assegurados para todos.

As políticas educacionais dos anos de 1990 são entendidas como discursos e dispositivos de uma mentalidade neoliberal, que fornecem uma série de ordenamento separam a organização dos currículos e do ensino e criam um campo de possibilidades para a ação dos professores e de outros agentes educacionais. A averiguação de que as alterações mais recentes na organização escolar demonstram uma maior flexibilidade, tanto nos processos avaliativos quanto nas estruturas curriculares, surge a idéia do aparecimento de novos padrões organizacionais também do trabalho escolar, exigentes de novo perfil de trabalhadores docentes.

As reformas educacionais brasileiras apresentam como característica comum a "tentativa de melhorar as economias nacionais pelo fortalecimento dos laços entre escolarização, trabalho, produtividade, serviços e mercados sendo vista pelos 
governantes como uma possibilidade de ingresso no marcado capitalista mundial". (AZEVEDO, 2004, p.7-8)

Entre as metas desse documento estão a "descentralização da administração das verbas federais, elaboração do currículo básico nacional, educação à distância, avaliação nacional das escolas, incentivo à formação de professores". (LIBÂNEO; OLIVEIRA; TOSCHI, 2005, p. 34).

Esse novo modelo de formação de professores colaborou para a precarização da formação docente, desvalorizando as dimensões políticas e éticas da formação e apresentando um retrocesso à luta dos educadores pela melhoria da qualidade educacional do país. (BRITO, 2008).

Nesse contexto, é possível observar nesse período um duplo enfoque nas reformas educacionais: a educação voltada à formação para o trabalho e a educação pautada na gestão ou disciplina da pobreza.

Segundo Garcia e Anadon (2009), entre os aspectos e as mudanças que apontam para a precarização do trabalho dos professores podem-se destacar

a desqualificação da formação profissional dos docentes pela pedagogia oficial das competências, a intensificação do trabalho dos professores em decorrência do alargamento das funções no trabalho escolar e das jornadas de trabalho, os baixos salários docentes que não recompuseram as perdas significativas que sofreram nos anos da ditadura militar. Também a padronização dos currículos do ensino básico e da formação docente e a instituição de exames nacionais favoreceram a emergência de novas estratégias de controle, baseadas na auditoria, no desempenho e no recrudescimento da culpa e da autorresponsabilização docentes. Essas estratégias estão deslocando, em parte, formas de controle do trabalho docente que predominaram na organização curricular da década de 1970, baseadas na vigilância e supervisão direta dos professores pelos chamados especialistas da educação e na demanda intensa de trabalho burocrático para prestação de contas do ensino. (GARCIA, ANADON, 2009, p.67)

De acordo com Enguita (1991), a urbanização e a expansão do ensino público e privado, e a conseqüente hierarquização da organização escolar, com a figura do diretor e dos especialistas educacionais, resultaram numa redução da autonomia docente no processo educacional. A padronização dos programas de ensino e dos currículos escolares contribuiu para uma diminuição na participação do professor no 
resultado do seu trabalho, já que estas regulamentações influenciam no conteúdo que o professor deve ensinar e em como ele irá ensinar.

A crescente desqualificação e fragmentação do seu trabalho, a "popularização" do ato de ensinar, o desprestígio social da ocupação, a baixa remuneração e a presença dos especialistas na escola são fatores que induzem a categoria à sua proletarização. Nesses trabalhos, a proletarização é analisada a partir das implicações do capitalismo sobre as especificidades do trabalho do professor em seu fazer pedagógico e as conseqüências deste movimento na autonomia e no controle do professor em relação ao seu trabalho.

O entendimento das reformas educacionais como dispositivos de recomposição dos mecanismos de regulação social no interior dos aparatos educacionais e escolares, e de instituição de novas racionalidades de governo dos diferentes agentes educacionais, como os professores, é o horizonte conceitual da análise dessa pesquisa. As políticas educacionais dos anos de 1990 são entendidas como discursos e dispositivos de uma mentalidade neoliberal, que fornecem uma série de ordenamento separam a organização dos currículos e do ensino e criam um campo de possibilidades para a ação dos professores e de outros agentes educacionais. A averiguação de que as alterações mais recentes na organização escolar demonstram uma maior flexibilidade, tanto nos processos avaliativos quanto nas estruturas curriculares, surge a ideia do aparecimento de novos padrões organizacionais também no trabalho escolar, exigentes de novo perfil de trabalhadores docentes.

\section{A NATUREZA DO TRABALHO DOCENTE EM MINAS GERAIS}

Buscou-se de entrevista semi-estruturada realizada com 3 membros do SindiUTE - Patos de Minas/MG compreender a representação dos sujeitos entrevistados sobre a natureza do trabalho docente antes e depois das reformas educacionais dos anos 1990. As entrevistadas colocaram que os professores ainda têm vontade de ensinar, de fazer o trabalho bem feito, mas, pela necessidade de lecionar em mais de uma escola, falta tempo para executar suas tarefas. Além do problema de indisciplina por parte dos alunos, da sobrecarga de trabalho e falta de material didático também são ressaltados. 
Sobre as mudanças no perfil do professor dos anos 1990 e dos professores nos dias atuais, as entrevistadas afirmam que houve grande redução no nível de reconhecimento profissional por parte do Estado, e também que a formação acadêmica era melhor estruturada antes nos anos 1990.

De acordo com a Secretaria Estadual de Educação/MG (2011), a caracterização do trabalho docente em Minas Gerais a contratação dos professores passam por 3 categorias: professores efetivos, efetivados e designados. OS professores efetivos são os que entraram no Estado através de concurso público, o professor designado, entrou no Estado através da LC n¹00, que amparou o professor efetivado, garantido seu cargo no Estado por tempo indeterminado e o professor designado, que trabalha com as vagas remanescentes das escolas e com contrato por tempo previamente estabelecido.

\section{OS PROCESSOS DE PRECARIZAÇÃO E INTENSIFICAÇÃO DO TRABALHO DOCENTE}

Para ter conhecimento sobre os processos de precarização que os professores passam, foram abordadas questões sobre essa temática.

As entrevistadas definem precarização do trabalho docente como redução dos direitos dos professores e aumento das suas obrigações dentro e fora da sala de aula - atuando, às vezes, em funções que não são características da profissão docente.

Outro fator apontado quanto à precarização foi a política salarial implementada desde o governo de Aécio Neves (2002 -2010). A Entrevistada A coloca que o sindicato está lutando por um piso salarial nacional, que está na Constituição Federal de 1988.

A Lei Federal $\mathrm{n}^{\circ} 11738$ de 16 de julho de 2008 coloca o piso salarial nacional no valor de $R \$ 1.187,14$ e define que

Esta Lei regulamenta o piso salarial profissional nacional para os profissionais do magistério público da educação básica a que se refere a alínea "e" do inciso III do caput do art. 60 do Ato das Disposições Constitucionais Transitórias.(LEI 11.738, de 16/07/2008, art. $1^{\circ}$ ) 
Atualmente, em Minas Gerais, no governo de Antônio Anastasia (2011- ) foi adotada uma nova política remuneratória para as carreiras dos servidores da Educação: é o sistema de remuneração de pagamento por subsídio. Nesse tipo de remuneração, todas as vantagens são incorporadas ao valor total pago, não existindo plano de carreira, conforme mostra o artigo $2^{\circ}$ da Lei 11.738 .

Segundo as entrevistadas, com o pagamento do subsídio, os professores não têm direitos de salário indireto como: serviço de transporte, creche, salário-família, vale alimentação, cesta básica de alimentos, auxílio estudo, vale transporte e auxílio creche. Os benefícios que os servidores públicos da educação recebem são o plano de saúde e assistência odontológica.

Segundo o sindicato, a política salarial adotada é a mesma para efetivos, efetivados e contratados, com os mesmos direitos e deveres para todas as categorias.

Quanto à intensificação do trabalho docente, o sindicato entende que essa intensificação ocorre devido ao acúmulo de trabalho em consonância com os baixos salários e a cobrança dos programas de controle de qualidade impostos pelo governo. Os professores vêem-se obrigados a trabalhar em mais de uma escola para conseguirem manter um salário digno. As entrevistadas colocam que existe uma cobrança excessiva por parte do Estado, com relação a resultados, e que o professor precisa trabalhar fora do horário de trabalho remunerado para conseguir cumprir com todas as obrigações que Ihe são impostas- planejar aulas, elaborar e corrigir provas e estudar o conteúdo.

\section{CONSIDERAÇÕES FINAIS}

A presente pesquisa teve como foco as implicações das políticas públicas na reestruturação produtiva do mundo do trabalho dos professores na rede estadual de ensino do Estado de Minas Gerais, mais especificamente, da cidade de Patos de Minas/MG.

Para isso as reflexões levaram em consideração, sobretudo, as políticas públicas que orientam a reestruturação produtiva na esfera educacional e seus impactos no trabalho docente da rede pública estadual de Minas Gerais, a partir de 1990 quando se intensificam as reformas educacionais no Brasil e em Minas Gerais. 
O trabalho docente encontra-se inserido no contexto dessas transformações advindas do neoliberalismo. Os professores têm sofrido relativa precarização nos aspectos relativos à empregabilidade.

O aumento dos contratos temporários nas redes públicas de ensino, o arrocho salarial, o respeito a um piso salarial nacional, a inadequação ou mesmo ausência, em alguns casos, de planos de cargos e salários, a perda de garantias trabalhistas e previdenciárias vindas dos processos de reforma do Aparelho Estatal têm tornado cada vez mais agudo o quadro de instabilidade e precariedade do emprego no magistério público.

Foi realizada uma abordagem aprofundada sobre as reformas educacionais ocorridas nos anos 1990, com a promulgação da LDB 9394/96 que além de instituir a municipalização do ensino, aumentou as atribuições dos professores, nas quais os docentes passaram a se preocupar, além das questões relativas ao ensinoaprendizagem, com as atividades de gestão, planejamento, assistência e acompanhamento e integração escola-família-comunidade. Através dessa análise, foi possível perceber os indicativos do processo de precarização da função docente.

\section{REFERÊNCIAS BIBLIOGRÁFICAS}

ADAMI, A.S. et al. A formação do educador no movimento do capitalismo. In: Educare et educare: Revista em educação. V.1,.n.1, jan-jul 2006, p.245-250.

AUGUSTO, M.H.O.G. Trabalho docente e organização escolar na rede estadual de ensino em Minas Gerais. 2004. 192 f. Dissertação (Mestrado em Educação) FAE/UFMG, Belo Horizonte, 2004.

AZEVEDO, J.M.L. A educação como política pública. 3 ed. Campinas: Autores Associados, 2004.

BRITO, L. H. P. F. A educação na reestruturação produtiva do capital: um estudo sobre as reformas educativas e seu impacto no trabalho docente na rede estadual de ensino de 
Minas Gerais (2003 - 2008).171f.Dissertação (Mestrado em Educação) - FACEDUFU, Uberlândia, 2008.

CARNOY, M. Razões para investir em educação básica. Brasília: UNICEF/MEC, 1992.

DALE, R. Globalização e educação: demonstrando a existência de uma "cultura educacional mundial comum" ou localizando uma "agenda globalmente estruturada para a educação"? Educação \& sociedade, Campinas, v. 25, n. 87, maio-ago. 2004. p. 423-460.

ENGUITA, M.F. A ambigüidade da docência: entre o profissionalismo e a proletarização. Teoria \& Educação, Porto Alegre, n. 4, p. 41-61, 1991.

GARCIA, M. M. A., ANADON, S. B. Reforma educacional, intensificação e autointensificação do trabalho docente. Educ. Soc., Campinas, vol. 30, n. 106, p. 63-85, jan./abr. 2009 Disponível em <http://www.cedes.unicamp.br>. Acesso em 28 ago 2010.

KUENZER, A. Z. Ensino de $2^{\circ}$ grau: o trabalho como princípio educativo. $3^{a}$ Ed. São Paulo: Cortez, 1997.

LEHER, R. Da ideologia do desenvolvimento à ideologia da globalização: a educação como estratégia do Banco Mundial para "alívio" da pobreza. Tese de doutoramento apresentada à Faculdade de Educação da USP, SP, 1998.

LIBÂNEO,J.C.; OLIVEIRA,J.F.; TOSCHI, M.S. Educação escolar: políticas, estrutura e organização. 2 ed. São Paulo: Cortez, 2005.

MALANCHEN, J.,VIEIRA, S. da R.. A política brasileira de formação de professores: repercussões sobre o trabalho docente. In: VI seminário da redes trado: regulação educacional e trabalho docente. Rio de Janeiro: UERJ, 2006. 
MINAS GERAIS. Lei . $^{\circ} 11.738$, de 16 de julho de 2008. In: Secretaria de estado da educação de Minas Gerais, 2011. Disponível em:<http://hera.almg.gov.br/cgi-

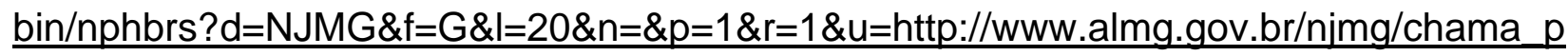
esquis

a.asp\&SECT1=IMAGE\&SECT2=THESOFF\&SECT3=PLUROFF\&SECT6=HITIMG\&SEC T7=LINKON\&SECT8=DIRINJMG\&SECT9=TODODOC\&C01=E\&CO2=E\&CO3=E\&CO4=E\& $\underline{s 1=L e i \& s 2=18975 \& s 3=2010 \& s 4=\& s 5}>$ Acesso em 30 out 2011.

MIRANDA, K. As transformações contemporâneas no trabalho docente: recuperação em sua natureza e seu processo de trabalho. In: VI Simpósio da DERESTRADO. Regulação Educacional e Trabalho Docente. Rio de Janeiro, 2006.

NAGEL, L. H.. A sociedade do conhecimento no conhecimento dos educadores. Texto aprovado e publicado nos Anais (em CD-ROM) do I Seminário Internacional de Educação. Cianorte: 2001. [Arquivo: SOCIEDconhecim]

NOGUEIRA, E. S. Políticas de formação de professores: a formação cindida (1995 2002). Tese de doutorado. Defendida no Programa de Pós-Graduação em Educação na UFRJ, 2003, $198 \mathrm{p}$.

OLIVEIRA, D.A. A reestruturação do trabalho docente: precarização e flexibilização. Educação \&. Sociedade. [online]. 2004, vol.25, n.89, pp. 1127-1144.

SILVA JÚNIOR, J.R. Reforma do Estado e da educação no Brasil de FHC. São Paulo: Xamã, 2002.

SILVA, M. V. Empresa e escola: Do discurso da sedução a uma relação complexa. 2007. Tese (Doutorado em Educação) - Faculdade de Educação, Universidade Estadual de Campinas, Campinas, 2007. 
* Mestranda do Programa de Pós-Graduação em Educação da Universidade Federal de Uberlândia. PPGED/FACED/UFU. Bolsista CAPES, período: 2010-2011. Membro do Grupo de Pesquisa em Trabalho, Educação e Sociedade -GPTES.

* Doutora em Ciências Sociais na Universidade Federal de Uberlândia; Professora do Programa de PósGraduação em Educação PPGED/FACED/UFU. Coordenadora do GPTES. Apoio Fapemig.

ENVIADO EM: 17.10. 2011

APROVADO EM: 18.11. 2011 